Delisi, Mathew, Andrew L. Hochstetler, and Daniel S. Murphy. (2003) Self Control Behind Bars: A Validation Study of the Grasmick et al. Scale. Justice Quarterly, 20(2): 241-263. Version of record published by Taylor \& Francis for the Academy of Criminal Justice Sciences, www.informaworld.com (ISSN: 0741-8825) DOI: 10.1080/07418820300095521 (June 2003)

\title{
Self-Control Behind Bars: a Validation Study of the Grasmick et al. Scale
}

\author{
Matt Delisi, Andy Hochstetler, Daniel S. Murphy
}

\begin{abstract}
Much empirical support of self-control theory is based on the 24-item scale conceptualized by Grasmick and his colleagues. This study examined the dimensionality of the scale. Exploratory factor analysis, confirmatory factor analyses, and a structural equation model (SEM) produced results that are discordant with much prior research. The Grasmick et al. scale was not unidimensional, more complex theoretical iterations failed to meet most goodness-of-fit statistics, and considerable refinement via modification indices was needed before a measurement model that fit the data could be found. Further refinement is required to justify it as the quintessential measure of self-control.
\end{abstract}

\section{ARTICLE}

Much empirical support of self-control theory is based on the 24-item scale conceptualized by Grasmick and his colleagues. This study examined the dimensionality of the scale. Exploratory factor analysis, confirmatory factor analyses, and a structural equation model (SEM) produced results that are discordant with much prior research. The Grasmick et al. scale was not unidimensional, more complex theoretical iterations failed to meet most goodness-of-fit statistics, and considerable refinement via modification indices was needed before a measurement model that fit the data could be found. Further refinement is required to justify it as the quintessential measure of self-control.

Gottfredson and Hirschi's A General Theory of Crime (1990) galvanized the criminological community with its assertion that self-control is the main individual-level predictor of delinquency and related deviant behaviors. According to Pratt and Cullen (2000, p. 931), the popularity, controversy, and accuracy of self-control theory are some of the reasons why its authors are among the most cited criminologists in the world. Since 1990, dozens of scholars have devised ways to operationalize self-control and to examine its predictive power empirically. 
To date, the most widely used measure of self-control is the 24-item, six-factor scale, developed by Grasmick, Tittle, Bursik, and Arneklev (1993), a measure often referred to as the Grasmick et al. scale. This article rigorously examines the validity and reliability of this scale using exploratory factor analysis, confirmatory factor analysis, a refined measurement model, and an SEM.

\section{THEORETICAL AND EMPIRICAL BACKGROUND}

According to Gottfredson and Hirschi (1990), ineffective parenting is the crucible that forges low self-control. A variety of characteristics and behaviors typify ineffective parenting, including poor monitoring of children's behavior, the inability or reluctance to recognize children's deviance, and the unwillingness to punish children for their misdeeds. Primary caregivers who fail or are unable to invest and participate fully in the responsibilities inherent in rearing children fail to instill self-control. Unfortunately, children who experience perfunctory socialization lack the gumption, wherewithal, or self-control to succeed in life.

Persons with low self-control (1) have a here-and-now orientation, so that they seek immediate, not delayed, gratification; (2) prefer easy and simple endeavors and tend to dislike activities that require diligence, tenacity, and persistence; (3) engage in risky and exciting, rather than cautious and cognitive, behaviors; (4) fail to see the long-term benefits of investing in social institutions; (5) are attracted to endeavors that entail little skill or planning; and (6) are unkind, insensitive, self-centered, and unempathic to others (Gottfredson \& Hirschi, 1990). Neglectful or abject parenting produces the aforementioned constellation of traits in children by age 8 , and levels of self-control remain relatively stable thereafter. Although self-control is a unitary latent construct, it can manifest itself in an array of deleterious ways, including drinking alcohol; gambling; engaging in sexual promiscuity; smoking; erratic or accident-prone driving; and being indifferent to school, primary relationships, and work. These versatile behavioral outcomes are illustrative of the "generality" of self-control. What is most important, Gottfredson and Hirschi asserted that persons with low self-control are disproportionately likely to engage in crime and delinquency.

Although Gottfredson and Hirschi's brazen claims about their theory's generality and predictive power have certainly made them vulnerable to criticism, the empirical evidence has generally supported their theoretical claims about the influence of self-control on crime and analogous behaviors. Persons with low levels of self-control are more likely to be involved in traffic accidents (Junger \& Tremblay, 1999), less likely to wear seat belts (Keane, Maxim, \& Teevan, 1993), and are prone to drive while intoxicated or indicate that they would do so (Keane et al., 1993; Piquero \& Tibbetts, 1996). Self-control is significantly related, in the expected direction, to academic dishonesty (Cochran, Wood, Sellers, Wilkerson, \& Chamlin, 1998); cutting class (Gibbs \& Giever, 1995); and involvement in an assortment of imprudent behaviors, such as gambling, drinking, smoking, and substance abuse (Arneklev, Grasmick, Tittle, \& Bursik, 1993; Forde \& Kennedy, 1997; Gibbs \& Giever, 1995). Gottfredson and Hirschi (1990) stated that in its most elemental form, crime entails acts of "force" and "fraud," and researchers have found that self-control predicts disparate acts of "force" and "fraud" (Britt, 2000; Brownfield \& Sorenson, 1993; Burton, Cullen, Evans, Fiftal-Alarid, \& Dunaway, 1998; DeLisi 2001a, 2001b; Gibbs, Giever, \& Martin, 1998; Gibson \& Wright, 2001; Grasmick et al., 1993; LaGrange \& 
Silverman, 1999; Longshore, 1998; Longshore \& Turner, 1998; Nagin \& Paternoster, 1993; Piquero \& Tibbetts, 1996; Polakowski, 1994; Schreck 1999; Sellers 1999; Wright \& Cullen, 2000).

In their comprehensive meta-analysis of the empirical tests of self-control theory, Pratt and Cullen (2000) reviewed 21 studies that included 17 independent data sets and 49,727 individual cases. They assessed the relationships of the effect-size estimates of 126 self-control measures to crime-related dependent variables. Overall, they found that self-control, with an effect size of .20 , was one of the strongest known correlates of crime. Indeed, Pratt and Cullen (2000, p. 952) stated that "future research that omits self-control from its empirical analyses risks being misspecified."

Despite this empirical validation, the self-control construct has been subjected to considerable theoretical criticism (see Geis, 2000). Noting that self-control measures explain relatively low levels of variation in crime-related dependent variables, some researchers have questioned Gottfredson and Hirschi's (1990) bold assertion that self-control is the indispensable predictor of crime (Arneklev et al., 1993; Brownfield \& Sorenson, 1993; Grasmick et al., 1993; Junger \& Tremblay, 1999; Sellers, 1999). Indeed, investigators have found that the effects of self-control are exceeded by measures from competing theoretical perspectives, such as strain, rational choice, and Baumrind's theory of authoritative parenting (Hay, 2001; Tibbetts \& Myers, 1999; Van Wyk, Benson, \& Harris, 2000; cf. Britt, 2000; Polakowski, 1994).

Theoretical critiques of self-control theory have taken two general forms. First, self-control theory has often been pitted against social learning and differential association theories when the strong effects of peer associations on delinquency are examined. Self-control theorists have generally asserted a "birds of a feather" perspective in which peer associations are rendered spurious because criminal offenders self-select deviant peers. In other words, the reason that peer associations appear to be related to crime is that criminals are more likely to fraternize with persons like themselves. Others, however, have suggested that social learning processes, particularly those learned from association with delinquent peers, mediate the effects of selfcontrol (Avakame, 1998; Gibson \& Wright, 2001; Winfree \& Bernat, 1998). For example, Gibson and Wright (2001) found that the interaction between self-control and delinquent peers is potentially the most fruitful indicator of criminal involvement (also see Wood, Cochran, Pfefferbaum, \& Arneklev, 1995).

Second, the static nature of A General Theory of Crime has often been criticized as being overly simplistic and unable to explain appropriately changes in criminal behavior over the life course. Conversely, developmental theories are able to address both stability and change in patterns of offending by demonstrating the salience of social institutions, such as work, marriage, school, and the military. The relative merits of general and developmental theories have been debated by Gottfredson and Hirschi (1990; see also Hirschi \& Gottfredson, 1989, 1993, 1995) and their developmentally inclined critics (Paternoster \& Brame, 1997; Sampson and Laub, 1993, 1995) and have frequently appeared in the literature. In fact, a number of scholars have conducted "head-to-head" tests between developmental and self-control models and found that delinquency is better explained by the former perspective (Bartusch, Lynam, Moffitt, \& Silva, 1997; Moffitt, Krueger, Caspi, \& Fagan, 2000; Wright, Caspi, Moffitt, \& Silva, 1999). In addition to theoretical 
exchanges and tests, methodological debates also continue over how to operationalize selfcontrol most appropriately and the place that Gottfredson and Hirschi's theory should play in measurement.

\section{THE GRASMICK ET AL. SELF-CONTROL SCALE}

The Grasmick et al. (1993) scale contains 24 attitudinal items, 4 for each of the 6 characteristics of self-control described by Gottfredson and Hirschi (1990). The 6 characteristics are operationalized with Likert-scale responses (e.g., strongly disagree to strongly agree) to four statements.

Impulsivity is operationalized with Item 1, "I often act on the spur of the moment without stopping to think"; Item 2, "I don't devote much thought and effort to preparing for the future"; Item 3, "I often do whatever brings me pleasure here and now, even at the cost of some distant goal"; and Item 4, "I'm more concerned with what happens to me in the short run than in the long run." Simple Tasks is operationalized with Item 5, "I frequently try to avoid projects that I know will be difficult"; Item 6, "When things get complicated, I tend to quit or withdraw"; Item 7, "The things in life that are easiest to do bring me the most pleasure"; and Item 8, "I dislike really hard tasks that stretch my abilities to the limit." Risk seeking is operationalized with Item 9, "I like to test myself every now and then by doing something a little risky"; Item 10, "Sometimes I will take a risk just for the fun of it"; Item 11, "I sometimes find it exciting to do things for which I might get in trouble"; and Item 12, "Excitement and adventure are more important to me than security." Physical Activities is operationalized with Item 13, "If I had a choice, I would almost always rather do something physical than something mental"; Item 14, "I almost always feel better when I am on the move than when I am sitting and thinking"; Item 15, "I like to get out and do things more than I like to read or contemplate things"; and Item 16, "I seem to have more energy and a greater need for activity than most other people my age." Self-centeredness is operationalized with Item 17, "I try to look out for myself first, even if it means making things difficult for other people"; Item 18, "I'm not very sympathetic to other people when they are having problems"; Item 19, "If things I do upset people, it's their problem not mine"; and Item 20 , "I will try to get things I want even when I know it's causing problems for other people." Finally, Temper is operationalized with Item 21, "I lose my temper pretty easily"; Item 22, "Often, when I'm angry at people, I feel more like hurting them than talking to them about why I am angry"; Item 23, "When I'm really angry, other people better stay away from me"; and Item 24 , "When I have a serious disagreement with someone, it's usually hard for me to talk calmly about it without getting upset."

In the initial test of self-control theory, Grasmick et al. (1993) sampled 389 adult respondents using the Oklahoma City Survey. The respondents self-reported their involvement in a crime of force ("Have you used or threatened to use force against an adult to accomplish your goals?") and fraud ("Have you distorted the truth or falsely represented something to get something you couldn't otherwise obtain?"). Grasmick et al. found that low self-control, criminal opportunity, and the multiplicative term (self-control x opportunity) were significant predictors of the outcome variables. However, the direct effect of self-control was weaker than the other two measures. Furthermore, the explained variation was fairly modest: $22 \%$ for fraud and $26 \%$ for 
force. Grasmick et al. acknowledged two important findings that were supportive of the theory. First, exploratory factor analyses with one-, five-, and six-factor solutions and evaluative criteria, such as the Kaiser rule and scree discontinuity test, suggested that self-control was a unidimensional construct that encompassed the six characteristics described by Gottfredson and Hirschi (1990). Second, and most significant for the theory, self-control was found to predict force and fraud significantly.

In an accompanying study, Arneklev et al. (1993) used the original scale and the six scales formed from the underlying components to predict "imprudent" behaviors, such as smoking, drinking alcohol, and gambling. These dependent variables were selected to assess the potential generality of self-control beyond crime. Arneklev et al. found that self-control significantly predicted drinking and gambling, but not smoking. Moreover, the six factors variously predicted imprudent behaviors, with Simple Tasks and Physical Activities demonstrating the weakest predictive power. Wood, Pfefferbaum, and Arneklev (1993) also used exploratory factor analyses and found six factors with an eigenvalue greater than 1 and the largest change from the first to the second factor. However, they also found that not all components were equally predictive of crime, suggesting that the Grasmick et al. scale should be disaggregated and its components used as separate independent measures of personality traits. Similarly, Cochran et al. (1998) argued that the physicality element of the scale detracts from the scale's unidimensionality.

Nevertheless, it is now the norm to use the Grasmick et al. scale or some variation of it to test self-control theory empirically. In fact, 11 of the 21 studies reviewed by Pratt and Cullen (2000) used the scale. Self-control, operationalized by the Grasmick et al. scale, has consistently been linked to various types of deviance, including 17 forms of academic dishonesty (Cochran et al., 1998); index crimes from the Uniform Crime Reports (Longshore \& Turner, 1998; Longshore, Turner, \& Stein, 1996); sexual assault, theft, and drunk driving (Nagin \& Paternoster, 1993); and occupational deviance, including shortchanging a customer, using alcohol or drugs while working, lying to one's supervisor, calling in sick, and theft (Gibson \& Wright, 2001).

The disagreement surrounding the dimensionality of the Grasmick et al. self-control measure has led several researchers to conduct more sophisticated analyses, namely, confirmatory factors analyses. Unlike exploratory factor analysis, in which multiple variables are reduced without imposed theoretical structure to discover latent underlying factors, confirmatory factor analysis is designed to assess construct validity and therefore test theory. By specifying theoretically meaningful relationships, confirmatory factor analysis determines the goodness of fit between the observed covariances and hypothesized factor structures (see Gerbing \& Hamilton, 1996). Ultimately, confirmatory factor analysis will provide the evidence to support or refute the Grasmick et al. scale's dimensionality and, therefore, its validity. To date, some scholars have suggested that the six dimensions of self-control coalesce into one latent global trait (Arneklev, Grasmick, \& Bursik, 1999; Gibson \& Wright, 2001; Piquero \& Rosay, 1998; Vazsonyi, Pickering, Junger, \& Hessing, 2001), although others have disagreed (Greenberg, Tamarelli, \& Kelley, 2002; Longshore, Stein, \& Turner, 1998; Longshore \& Turner, 1998; Longshore et al., 1996). 
Despite the flurry of research surrounding A General Theory of Crime (Gottfredson \& Hirschi, 1990), many questions still exist about the tenability of self-control theory and the accuracy of the Grasmick et al. scale. Does self-control work differently for different populations? Is selfcontrol equally salient among low-risk samples, such as university students, and high-risk samples, such as prison inmates? What is the dimensionality of the scale? Is the scale a valid and reliable indicator of self-control? If so, can it be effectively used to predict assorted outcomes among diverse samples?

\section{CURRENT RESEARCH PURPOSES}

In this study, we addressed these questions and further refined the Grasmick et al. scale in three ways. First, we replicated the original scale and applied it to a sample of formerly incarcerated men, which extends the applicability of the scale to a criminal sample beyond that used by Longshore and his colleagues. Obviously, the validity of a measure, particularly one based on general theory, should not be contingent on the sample. Therefore, it was important to replicate the scale with offenders beyond Longshore's drug-offending California sample. Relatedly, with few exceptions (e.g., DeLisi 2001a, 2001b; Longshore et al., 1996, 1998), prior examinations of self-control theory have relied on samples with relatively low levels of criminality. Hirschi and Gottfredson (1993) explicitly recommended that researchers incorporate samples that provide adequate variation on crime-related dependent variables (see also, Paternoster \& Brame, 1997; Piquero \& Rosay, 1998; Vazsonyi et al., 2001). Toward this end, our sample consisted of parolees with various and often considerable criminal histories. This is an important step in determining the generality of self-control and its ability to explain offending among populations of offenders that are of most concern to society. Second, we conducted exploratory and confirmatory factor analyses to assess the dimensions of the scale. As Gerbing and Hamilton (1996) suggested, exploratory factor analysis is a useful heuristic approach to model specification, while confirmatory factor analysis is most appropriate for testing theory (see also, Vazsonyi et al., 2001). Third, we used a measurement model refined by modification indices in an SEM to examine the direct effects of self-control on two crime-based outcome variables.

\section{METHODS}

\section{Sample}

The data were derived from a stratified convenience sample of 208 male parolees residing in work-release facilities in a Midwestern state. Four geographically dispersed work-release facilities representing the most populous areas of the state were selected to maximize our efforts to represent the entire population of male work-release parolees. All the respondents had been released from state prison within the previous six months and were serving conditional parole sentences. Nonprobability convenience samples have serious limitations in terms of their generalizability; however, they are commonly used in tests of self-control theory (Pratt \& Cullen, 2000). Fortunately, the current offenders were selected from a sampling frame of only 480 parolees. Therefore, the sample encompassed $43 \%$ of the male work-release parole population. 1 


\section{Data Collection}

Brochures were disseminated at all work-release facilities to announce that researchers would be administering questionnaires in small groups. The questionnaires were voluntary and confidential, and offenders had the right to refuse to answer any question. From September through December 2001, the respondents were administered surveys in small groups that we proctored. They were paid $\$ 30$ for completing the surveys. The time needed to complete the questionnaires ranged from one to two hours. To accommodate the respondents' work and treatment schedules, we administered the surveys during standard business hours and evenings. All the respondents successfully completed the survey. This procedure was similar to face-toface interviews with a questionnaire because we were able to help the respondents understand the instrument, enhance the internal validity of the instrument by elucidating potentially unclear questions, and by assisting respondents with poor literacy skills. There are several benefits of this form of data collection (Maxfield \& Babbie, 2001).

\section{Survey Instrument and Grasmick et al. Scale}

The questionnaire yielded a wide array of information on the respondents, including their demographic characteristics; arrest and incarceration experiences; offending and victimization experiences while most recently incarcerated; and mental health/psychiatric histories before, during, and after their release from prison. Most important for our current purposes, the instrument includes the 24 attitudinal-items from the original Grasmick et al. scale. We coded most responses as strongly agree $=0$, agree $=1$, neutral $=2$, disagree $=3$, and strongly disagree $=4$ and reverse coded items when appropriate. Therefore, the respondents who scored low on the scale had low self-control (the original Grasmick et al. scale reverse coded the self-control measure). The items appear to measure the six components of the self-control construct reliably, evidenced by strong Cronbach's alpha coefficients for Impulsivity ([alpha] $=.79$ ), Simple Tasks $([$ alpha $]=.81)$, Risk Seeking $([$ alpha $]=.79)$, Physical Activities $([a l p h a]=.72)$, Selfcenteredness $([\mathrm{alpha}]=.81)$, and Temper $([\mathrm{alpha}]=.86)$. The Cronbach's alpha for the total scale was also strong $([$ alpha $]=.91) .2$

\section{Dependent Variables}

Persons who lack self-control are theorized to engage in a litany of behaviors, including crime, imprudent acts, and insensitive interpersonal behaviors. Two dependent variables, self-reported juvenile delinquency and adult prison offending, were used to assess the hypothesized generalized outcomes of low self-control.3 Juvenile delinquency consisted of the self-reported annual rate of involvement in assault/physical fights, weapons carrying, and theft ([alpha] = .74). Adult prison offending consisted of the self-reported annual rate of involvement in using, possessing, or selling alcohol and drugs; assaults/physical fights; and weapons carrying ([alpha] $=.76$ ). A recurrent criticism of self-control theory (e.g., Cochran et al., 1998; Grasmick et al., 1993; Sellers 1999; also see Hirschi \& Gottfredson, 1993) is that self-control theory minimizes the role of opportunity in criminal offending. The current operationalization controls for time by turning counts into rates. 


\section{Independent Variables}

In A General Theory of Crime, Gottfredson and Hirschi (1990) extensively discussed the important predictive power of race and age. The theoretical usefulness of these and other variables is briefly discussed here.

Race. Gottfredson and Hirschi (1990) suggested that racial and ethnic differences in criminal offending and victimization are the probable outcome of differences in child-rearing practices. Racial groups (e.g., African Americans) with high levels of family dissolution and illegitimacy are more likely to experience the strained childhood socialization processes that produce low self-control. It is arguable, for example, that single parents have more difficulty monitoring their children's behavior because of their work responsibilities. Consequently, children in singleparent homes are more likely to be unmonitored vis-a-vis children from two-parent homes. The majority of the offenders in the sample, $61 \%$, were white, and the remaining $39 \%$ were nonwhite. To assess these potential effects, race-ethnicity was dichotomized (white $=0$, nonwhite =1).

Age. Gottfredson and Hirschi (1990) and Hirschi and Gottfredson (1983) asserted that involvement in crime peaks in late adolescence-early adulthood and declines steadily thereafter. This inverse relationship persists regardless of time, space, or context. In their words, the agecrime relationship is "invariant." The average age of the respondents in our study was approximately 29 years. Age was operationalized as an ordinal variable, ranging from age 15 or $16=1$ to age 31 or older $=6$.

\section{Analytical Procedures}

To examine the dimensionality and validity of the Grasmick et al. scale, we conducted exploratory and confirmatory factor analyses. Exploratory factor analysis determines the number of factors that account for the covariation between the 24 items in the scale. Prior research (Arneklev et al., 1993; Grasmick et al., 1993; Piquero et al., 2000; Vazsonyi et al., 2001) suggested that six factors will emerge with an eigenvalue greater than 1 . These factors represent the six theorized dimensions of self-control. Furthermore, a large drop in eigenvalues between the first and second factor supposedly suggests that the Grasmick et al. scale is unidimensional. Limitations of exploratory factor analysis (see Arneklev et al., 1999; Greenberg, 2000;

Greenberg et al., 2002; Piquero \& Rosay, 1998; Vazsonyi et al., 2001) have prompted the use of confirmatory factor analyses to assess the goodness of fit between theoretically guided factors and the observed data. Confirmatory factor analysis models were run to evaluate three theoretical interpretations of the item, dimension, and self-control structure: (1) six separate factors, (2) second-order analysis with six separate factors and the overall self-control construct, and (3) all 24 items loading onto one factor. The best model was then refined using modification indices and was used in an SEM with two controls representing ascribed demographic characteristics (age and race) and the two dependent variables. 


\section{FINDINGS}

\section{Exploratory Factor Analysis}

Like Grasmick et al.'s (1993) original research, principal component exploratory factor analysis with no rotation yielded six eigenvalues greater than 1, which, according to the Kaiser rule, is an appropriate determination of factors. As Table 1 shows, these factors are Factor 1 (eigenvalue $=$ 7.906), Factor 2 (eigenvalue $=2.411$ ), Factor 3 (eigenvalue $=1.827)$, Factor 4 (eigenvalue $=$ 1.397), Factor 5 (eigenvalue $=1.251)$, and Factor 6 (eigenvalue $=1.052)$. Varimax (orthogonal) and promax (oblique) rotation yielded six substantively similar factors. Taken together, the six factors appear to represent the compositional elements of self-control theorized by Gottfredson and Hirschi (1990). Finally, the scree discontinuity test indicates that the greatest difference between adjacent factors occurs between the first and second, an eigenvalue difference of 5.495. Similar findings often lead to the conclusion that the scale is unidimensional.

\section{Table 1. Exploratory Factor Analysis}

\begin{tabular}{llll}
\hline Factor 1: & 7.90622 & Factor 4: & 1.39722 \\
Factor 2: & 2.41144 & Factor 5: & 1.25082 \\
Factor 3: & 1.82727 & Factor 6: & 1.05174
\end{tabular}

Loadings on Factor 1

\begin{tabular}{|c|c|}
\hline Item 1 & .70846 \\
\hline Item 2 & .46163 \\
\hline Item 3 & .67652 \\
\hline Item 4 & .61121 \\
\hline Item 5 & .58536 \\
\hline Item 6 & .59762 \\
\hline Item 7 & .44282 \\
\hline Item 8 & .44861 \\
\hline Item 9 & .44463 \\
\hline Item 10 & .52109 \\
\hline Item 11 & .63587 \\
\hline Item 12 & .64987 \\
\hline Item 13 & .3457 \\
\hline Item 14 & .5496 \\
\hline Item 15 & .42989 \\
\hline Item 16 & .25327 \\
\hline Item 17 & .6077 \\
\hline Item 18 & .5384 \\
\hline Item 19 & .54572 \\
\hline Item 20 & .72758 \\
\hline Item 21 & .6936 \\
\hline Item 22 & .70660 \\
\hline Item 23 & .66259 \\
\hline Item 24 & .6248 \\
\hline
\end{tabular}




\section{Model Testing}

On the basis of reasonable theoretical interpretations of the expected factor structure, we conducted three confirmatory factor analyses: the six-factor model (see Table 2), the secondorder model with seven factors (see Table 3), and the model in which all 24 items loaded on one factor (see Table 4). The model with the six latent variables indicates that all factor loadings are significant at the $\mathrm{p}<.05$ level. The $[\mathrm{chi}]^{\wedge} \mathrm{sub} 2^{\wedge} / \mathrm{df}$ ratio is $439.27 / 237=1.855$. This fit statistic tests the null hypothesis that there is no statistically significant difference in the observed and theoretical covariance structure matrices. The preferred value of [chi] ${ }^{\wedge} \mathrm{sub} 2^{\wedge} / \mathrm{df}$ should be less than $2: 1$. The current value of 1.855 narrowly meets the criterion. To examine the structures further, we transformed the $[\mathrm{chi}]^{\wedge} \operatorname{sub} 2^{\wedge}$ to a $\mathrm{z}$-score using the formula $\mathrm{z}=\operatorname{sqr}\left(2[\mathrm{chi}]^{\wedge} \operatorname{sub} 2^{\wedge} /\right)$ sqr (2df -1). The transformation procedure yielded a $\mathrm{z}=7.891$, a value that caused us to reject the model confidently. The root mean square error of approximation (RMSEA) is a fit statistic that is less susceptible to sample size than is [chi $]^{\wedge} \sup 2^{\wedge} / \mathrm{df}$. Although previous researchers (e.g., Vazsonyi et al., 2001) have used RMSEA <.1 as a good fit, others (e.g., Steiger, 1998, 2000) have suggested that RMSEA values of .05 or less are obviously more acceptable. The six-factor RMSEA = .06 suggests a poor fit (but see $\mathrm{Hu} \&$ Bentler, 1999; Piquero et al., 2000). Three final goodness-of-fit statistics were examined. The goodness-of-fit index (GFI) is a measure of the discrepancy between predicted and observed covariances. Values should exceed .90. The current $\mathrm{GFI}=.852$. The adjusted goodness-of-fit index (AGFI) adjusts the GFI for degrees of freedom. Critical values should exceed .90 ; the current AGFI $=.812$. Both indices indicate a poor fit and discourage acceptance of the model. Finally, the root mean square residual (RMR) measure is the square root of the average squared amount by which the sample covariances differ from the estimates in the model. Critical values should be less than .10 . The model RMR $=.066$, suggesting a moderately good fit. 4 Each of the six dimensions was correlated with the others. The weakest correlation was Self-centered and Simple Tasks $(r=.053)$ and the strongest Was Simple Tasks and Temper $(\mathrm{r}=.084)$. These correlations are well below conventional psychometric standards for establishing convergent validity. The average correlation among all the dimensions was $r=.072$. Results for this model appear in Table 2 . 
Table 2. Six-Factor Confirmatory Factor Analysis

\begin{tabular}{|c|c|c|c|c|c|c|}
\hline Variable & Factor 1 & Factor 2 & Factor 3 & Factor 4 & Factor 5 & Factor 6 \\
\hline $\begin{array}{r}\text { Impulsivity } \\
\text { Item } 1 \\
\text { Item } 2 \\
\text { Item } 3 \\
\text { Item } 4\end{array}$ & $\begin{array}{l}.77(.06)^{*} \\
.55(.07)^{*} \\
.77(.06)^{*} \\
.67(.07)^{*}\end{array}$ & & & & & \\
\hline $\begin{array}{c}\text { Physical Activity } \\
\text { Item } 1 \\
\text { Item } 2 \\
\text { Item } 3 \\
\text { Item } 4\end{array}$ & & $\begin{array}{l}.80(.06)^{*} \\
.81(.06)^{*} \\
.55(.07)^{*} \\
.72(.06)^{*}\end{array}$ & & & & \\
\hline $\begin{array}{r}\text { Risk Seeking } \\
\text { Item } 1 \\
\text { Item } 2 \\
\text { Item } 3 \\
\text { Item } 4\end{array}$ & & & $\begin{array}{l}.65(.07)^{*} \\
.73(.07)^{*} \\
.77(.06)^{*} \\
.63(.06)^{*}\end{array}$ & & & \\
\hline $\begin{array}{r}\text { Self-centered } \\
\text { Item } 1 \\
\text { Item } 2 \\
\text { Item } 3 \\
\text { Item } 4\end{array}$ & & & & $\begin{array}{l}.62(.07)^{*} \\
.75(.07)^{*} \\
.75(.07)^{*} \\
.38(.08)^{*}\end{array}$ & & \\
\hline $\begin{array}{r}\text { Simple Tasks } \\
\text { Item } 1 \\
\text { Item } 2 \\
\text { Item } 3 \\
\text { Item } 4\end{array}$ & & & & & $\begin{array}{l}.66(.07)^{*} \\
.63(.07)^{*} \\
.67(.06)^{*} \\
.92(.06)^{*}\end{array}$ & \\
\hline $\begin{array}{l}\text { Temper } \\
\text { Item } 1 \\
\text { Item } 2 \\
\text { Item } 3 \\
\text { Item } 4 \\
\end{array}$ & & & & & & $\begin{array}{l}.80(.06)^{*} \\
.81(.06)^{*} \\
.80(.06)^{*} \\
.71(.06)^{*}\end{array}$ \\
\hline
\end{tabular}

* $p<.05$.

Note: Coefficients are loadings with standard errors in parentheses. 


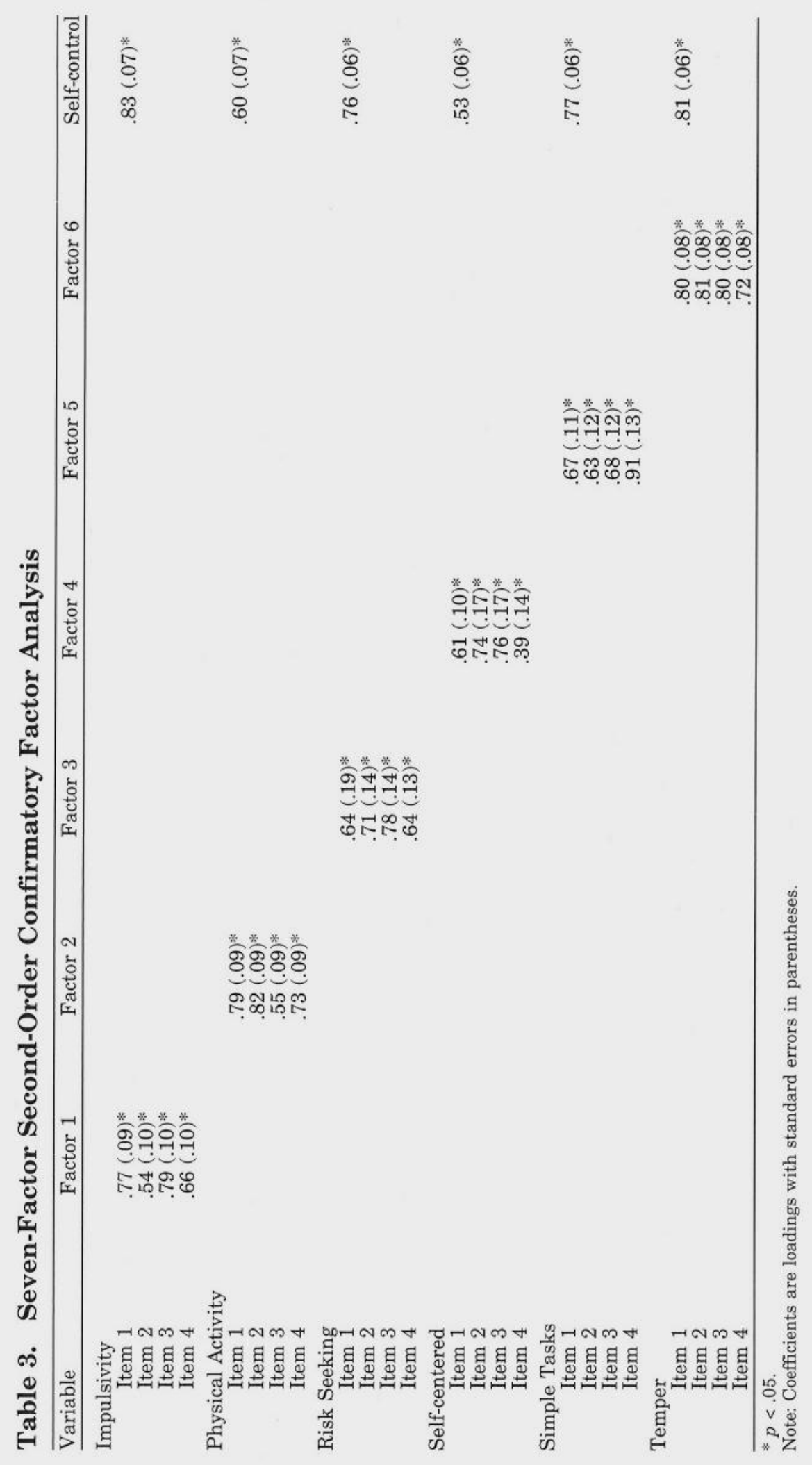




\section{Table 4. One-Factor Confirmatory Factor Analysis}

\begin{aligned} & \hline Variable Factor 1 \\ & \hline Impulsivity \\ & Item 1 $.69(.06)^{*} \\ &$ Item 2 $.41(.07)^{*} \\ &$ Item 3 $.65(.06)^{*} \\ &$ Item 4 $.56(.07)^{*} \\ &$ Physical Activity \\ & Item 1 $.53(.07)^{*} \\ &$ Item 2 $.54(.07)^{*} \\ &$ Item 3 $.39(.07)^{*} \\ &$ Item 4 $.39(.07)^{*} \\ &$ Risk Seeking \\ & Item 1 $.42(.07)^{*} \\ &$ Item 2 $.50(.07)^{*} \\ &$ Item 3 $.62(.06)^{*} \\ &$ Item 4 $.62(.07)^{*} \\ &$ Self-centered \\ & Item 1 $.29(.07)^{*} \\ &$ Item 2 $.49(.07)^{*} \\ &$ Item 3 $.37(.07)^{*} \\ &$ Item 4 $.22(.07)^{*} \\ &$ Simple Tasks \\ & Item 1 $.58(.07)^{*} \\ &$ Item 2 $.53(.07)^{*} \\ &$ Item 3 $.54(.07)^{*} \\ &$ Item 4 $.73(.06)^{*} \\ &$ Ttem 1 \\ & Item 2 $.70(.06)^{*} \\ &$ Item 3 $.72(.06)^{*} \\ &$ Item 4 $.67(.06)^{*} \\ & .63(.06)^{*} \\ &$\hline$p\end{aligned}$

$* p<.05$.

Note: Coefficients are loadings with standard errors in parentheses.

The next component of the confirmatory factor analysis is a second-order factor structure with seven latent variables identified: the six separate dimensions of self-control in addition to the overall latent trait. Overall, the second-order confirmatory factor model poorly fit the data. The $[\mathrm{chi}]^{\wedge} \sup 2^{\wedge} / \mathrm{df}$ was $485.54 / 246=1.974$, and $\mathrm{z}=\operatorname{sqr}\left(2[\mathrm{chi}]^{\wedge} \sup 2^{\wedge}\right)-\operatorname{sqr}(2 \mathrm{df}-1)=9.004$. These values indicate that the model should be confidently rejected. Furthermore, the RMSEA $=.07$, $\mathrm{GFI}=.837$, and AGFI $=.801$. Again, these fit statistics fail to meet the critical values and indicate a poor fit. In fact, the second-order $\mathrm{RMR}=.076$, the only fit statistic that indicates a good fit. Overall the loadings on the underlying self-control factor are .53 (Self-centered), .60 (Physical Activity), .76 (Risk Seeking), .77 (Simple Tasks), .81 (Temper), and .83 (Impulsivity). The results for this model appear in Table 3. 
As is shown in Table 4, the model with all 24 items on a single latent self-control factor had the worst fit among the confirmatory factor models, although all items loaded significantly at the $\mathrm{p}<$ .05 level. The $[\mathrm{chi}]^{\wedge} \sup 2^{\wedge} / \mathrm{df}$ was $1076.98 / 252=4.27$, which far exceeds the preferred value of $2: 1$. The remaining statistics indicate that the model is completely unacceptable. The $\mathrm{z}-\mathrm{score}=$ 23.983, $\mathrm{RMSEA}=.13, \mathrm{GFI}=.645, \mathrm{AGFI}=.578$, and $\mathrm{RMR}=.105$.

\section{Model Building}

Contrary to prior investigations, the current confirmatory factor analyses indicated that the Grasmick et al. scale is a poor measure of the self-control construct conceptualized by Gottfredson and Hirschi (1990). However, like previous researchers (e.g., Piquero et al., 2000), we found that the six-factor model was the most accurate model. Following modification indices, we used the following procedures to refine the six-factor model. Three items ("I act on the spur of the moment without stopping to think," "Excitement and adventure are more important to me than security," and "I try to avoid projects that I know will be difficult") were eliminated because they loaded strongly on more than two dimensions. In our opinion, each captures the general theoretical nature of self-control and would benefit from more-precise wording to discriminate and better reflect one dimension. The error terms for two redundant items ("I test myself by doing things that are a little risky" and "I take risks just for the fun of it") were correlated ( $\mathrm{r}=$ .46). These items are similar conceptually and contain similar key words. Error terms for two additional items ("I feel better when I am on the move than when I am sitting and thinking" and "I do the things in life that are the easiest and bring me the most pleasure") were correlated because of their similar word structure $(r=.24)$. We had no consistent theoretical or substantive rationale to correlate error terms of other items, although a few correlations would have improved the fit substantially. It is important to note that correlated error terms suggest that additional factors exist that are not specified by the measurement model. In this case, we argue that the factors result from imprecision in the wording of the items.

Finally, the error terms for two item-dimension interactions were correlated. Modification indices for the measurement model also suggested that items from one dimension were loading with another dimension, which means that the dimensions are not pure. The item "I devote time and effort to preparing for the future" from the Impulsivity dimension was correlated with the Temper dimension $(r=.20)$. The item "I am not very concerned about other people when they are having problems," originally from the Self-centered dimension, was correlated with the Simple Tasks dimension $(r=.16)$. After these considerable refinements, the measurement model's fit is greatly improved, as evidenced by the following goodness-of-fit statistics: $[\mathrm{chi}]^{\wedge} \sup 2^{\wedge}=193.99, \mathrm{p}=.01,[\mathrm{chi}]^{\wedge} \sup 2^{\wedge} / \mathrm{df}=193.99 / 170=1.14, \mathrm{z}=1.29$, RMSEA $=.03$, GFI $=.92, \mathrm{AGFI}=.89, \mathrm{RMR}=.045 .5$

\section{SEM}

The final analysis includes the refined six-factor measurement model and two ascribed demographic controls (age and race) in an SEM with two dependent variables: self-reported juvenile delinquency and adult prison offending. In this model, the fit statistics are [chi] $]^{\wedge} \sup 2^{\wedge}$ $=370.50, \mathrm{p}=.01,[\mathrm{chi}]^{\wedge} \sup 2^{\wedge} / \mathrm{df}=370.50 / 330=1.12, \mathrm{z}=1.55, \mathrm{RMSEA}=.02, \mathrm{GFI}=.90$, AGFI 
$=.86$, and RMR $=.047$. The SEM appears in Figure 1, and only significant paths are included. The only dimension of the measurement model derived from the Grasmick et al. scale that has modestly significant predictive power is Temper, which directly predicts juvenile delinquency ([beta] $=-.52, \mathrm{p}=.01)$. No other dimension (Impulsivity, Physical Activity, Risk Seeking, Selfcenteredness, or Simple Tasks) directly predicts juvenile delinquency or adult prison offending net the effects of controls. Thus, like prior researchers (e.g., Cochran et al., 1998; Wood et al., 1993), we found that the six factors have differential predictive power and may be fruitfully disaggregated and treated as separate independent variables. However, a more dramatic conclusion from the current analyses is that the predictive power of the Grasmick et al. scale is limited to a single dimension, in this instance, Temper.6

\section{Figure 1. Reduced Structural Equation Model with Standardized Coefficients Linking Offending to Dimensions of Self-control}

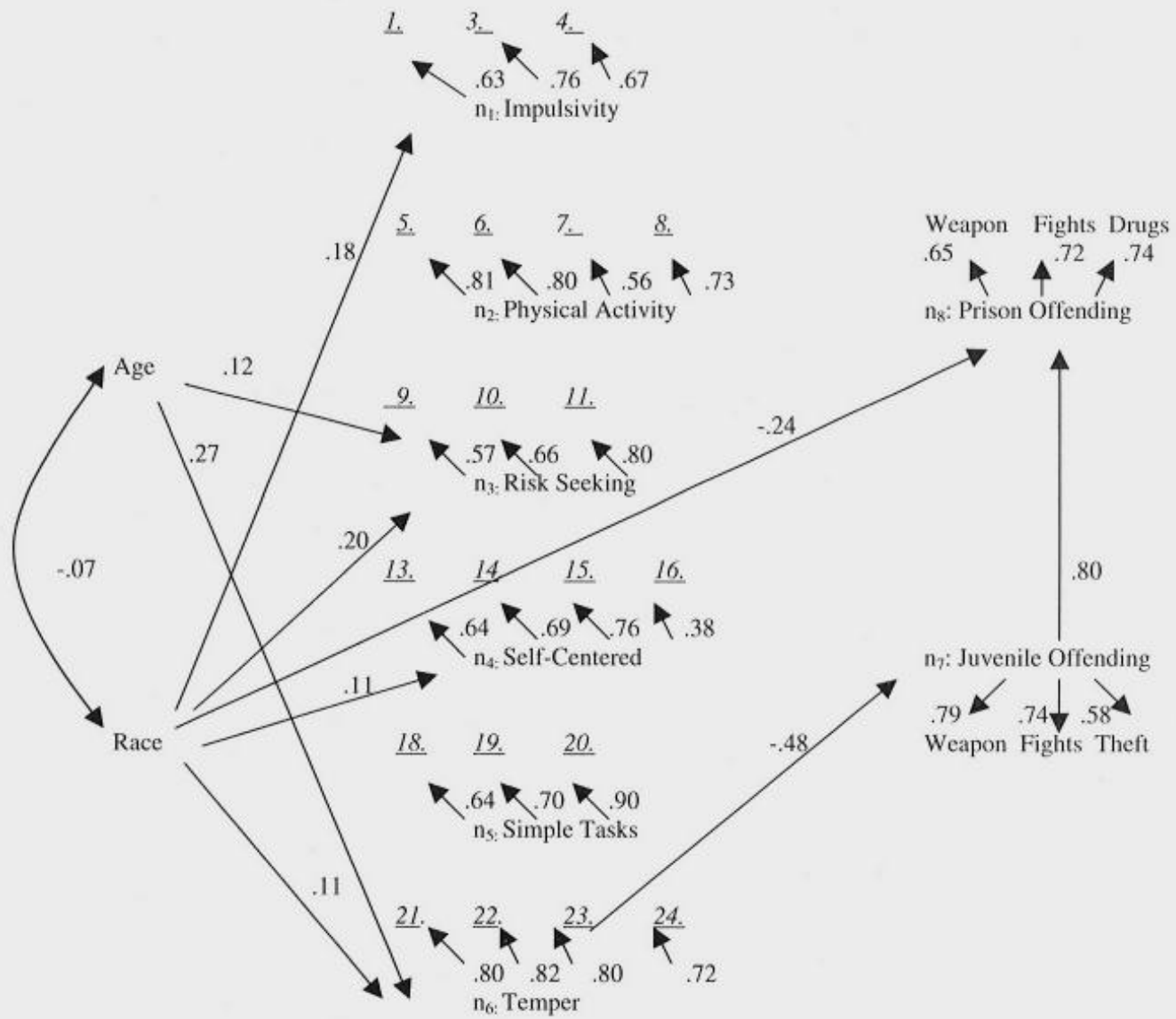

Note: For clarity of presentation, coefficients representing the correlations between the dimensions of self-control are not presented, although all are significant. All modifications remained significant but are not pictured.

The SEM also indicates that juvenile delinquency is a strong direct predictor of adult prison offending ([beta] $=.81, \mathrm{p}=.01)$. This behavioral continuity is independent of all dimensions of 
self-control. Age and race had modest direct effects on some of the six dimensions of self-control net the controls. For example, age directly and positively predicted two dimensions, Risk Seeking $([$ beta $]=.12, \mathrm{p}=.05)$ and Temper $([$ beta $]=.27, \mathrm{p}=.01)$. Age had no direct effect on either juvenile delinquency or adult prison offending. Black inmates scored higher than white inmates on Impulsivity ([beta] $=.18, \mathrm{p}=.03$ ), Risk Seeking ([beta] $=.20, \mathrm{p}=.03$ ), Selfcenteredness $([$ beta $]=.11, \mathrm{p}=.08)$, and Temper $([$ beta $]=.11, \mathrm{p}=.07)$. However, white inmates were more likely than black inmates to engage in adult prison offending ([beta] $=.24, p=.05$ ).7 Summary information for all the models appears in Table 5.

\section{Table 5. Summary Statistics for Exploratory Factor Analysis and Structural Equation Models}

\begin{tabular}{lrcrrrrrr}
\hline Model & \multicolumn{1}{c}{$\chi^{2}$} & $d f$ & $\chi^{2} / d f$ & $z$ & RMSEA & GFI & AGFI & RMR \\
\hline One factor & 1076.98 & 252 & 4.27 & 23.98 & .13 & .645 & .578 & .105 \\
Second order & 485.54 & 246 & 1.97 & 9.00 & .07 & .837 & .801 & .076 \\
Six factor & 439.27 & 237 & 1.86 & 7.89 & .06 & .852 & .812 & .066 \\
Refined six factor & 193.99 & 170 & 1.14 & 1.29 & .03 & .920 & .892 & .045 \\
SEM & 370.50 & 330 & 1.12 & 1.55 & .02 & .896 & .862 & .047 \\
\hline
\end{tabular}

\section{DISCUSSION AND CONCLUSION}

No research design is unassailable, and the current one is certainly no exception. Two caveats should be considered in interpreting these results. First, the external validity of findings that are based on nonprobability samples must always be interpreted cautiously. Like prior investigations (e.g., Arneklev et al., 1993, 1999; Grasmick et al., 1993; Longshore et al., 1996, 1998; Piquero \& Rosay, 1998; Piquero \& Tibbetts, 1996; Schreck, 1999), our sample was limited geographically. Until a national probability sample is administered a questionnaire with the Grasmick et al. scale, the generalizability of the measure will remain somewhat limited.

Second, the use of modification indices is somewhat controversial in an SEM because modifications fit the model to the data. Unless there are legitimate theoretical or conceptual reasons, the use of modification indices to improve model fit should be interpreted skeptically (see Silvia \& MacCallum, 1988). Indeed, the current measurement model required substantial improvements to arrive at an error structure with a good-enough fit to proceed with further analysis. Generally, the more modifications used to fit the model, the greater the chances the model will not replicate on future samples. This issue lies at the heart of the debate between previous scholars on the use of modification indices to refine the Grasmick et al. scale. For example, Piquero and Rosay (1998) declined to use modification indices, whereas Longshore et al. (1998) did use refinements. We agree with Longshore et al.'s (1998, p. 178) conclusion that "judicious and reasonable use of a small number of statistically significant and theoretically 
defensible supplementary correlations in a model with many degrees of freedom is not grounds for rejecting the results and, rather, is often encouraged" (see also, Li, Duncan, Harmer, Acock, \& Stoolmiller, 1998). Thus, it is essential for future research also to scrutinize the structure of the Grasmick et al. scale with different data.

This study used more conservative criteria for fit statistics and consequently concluded that the Grasmick et al. scale had a weaker fit. Researchers have used generous, probably too generous, critical values for goodness-of-fit statistics (cf. Longshore et al., 1998; Piquero \& Rosay, 1998; Piquero et al., 2000). In addition, our results suggest that the Temper dimension of the Grasmick et al. scale is most useful in predicting crime-related dependent variables. This Temper effect may be a function of the sample of offenders we used. The former inmates in this sample often had extensive criminal histories and had been involved in many physical confrontations and thus probably had these violent incidents in mind when they answered the queries about their temper. Several other researchers also found differential predictive power among the subscales of the Grasmick et al. scale. It is likely that the different dimensions (e.g., Temper, Impulsivity, Risk Seeking) of self-control will be differentially meaningful on the basis of the composition of the sample. For example, university undergraduates and convicted felons generally have disparate behavioral repertoires that make having a hot temper more salient for the latter group, especially when they reflect on their criminal histories.

Finally, Pratt and Cullen's (2000) meta-analysis of the literature on self-control found that behavioral measures of self-control are stronger than attitudinal ones like the Grasmick et al. scale. On this point, Gottfredson and Hirschi (1993) insisted that behavioral measures are the preferred method for testing their theory; unfortunately only a handful of researchers (DeLisi, 2001a, 2001b; Keane et al., 1993; Polakowski, 1994) have followed their advice. The validity of these behavioral measures is an open issue. What is clearer is the status of the Grasmick et al. scale. This study suggested that the scale is not unidimensional, more complex theoretical iterations failed to meet most goodness-of-fit statistics, and considerable refinement via modification indices was needed before a measurement model that fit the data could be found. Moreover, the Temper dimension was the only component of the scale that directly predicted criminal offending. Further refinement of the Grasmick et al. scale on additional validation samples is required to justify using the scale as the conventional measure of self-control.

\section{Footnotes}

* The authors acknowledge the helpful guidance of Professors David F. Greenberg and Fred Lorenz, the anonymous reviewers, and Donna Bishop on earlier drafts of this study. Direct correspondence to Professor Matt DeLisi, Department of Sociology, Iowa State University, 203A East Hall, Ames, IA 50011-1070; e-mail: delisi@iastate.edu.

1 Limited resources prevented the inclusion of female offenders in the sample. This is an admitted limitation of the data set, especially since prior researchers (Burton et al., 1998; LaGrange \& Silverman, 1999; Sellers 1999) found that self-control is a better predictor of delinquency among men than among women, suggesting a gender limitation for the construct. The population from which the sample was drawn is $72 \%$ white (sample: $61 \%$ white), $88 \%$ male 
(sample: $100 \%$ male), and approximately 31 years old (sample: average age is 29 years). Of the sample, 29\%; were incarcerated for violent crimes, and $22 \%$ were incarcerated for drug crimes. The respective population parameters were $28 \%$ and $22 \%$.

2 Prior researchers found that individual items detract from the Grasmick et al. scale's reliability, such as the first item for Physical Activities (Arneklev et al., 1993; Grasmick et al., 1993) and the first item for Impulsivity (Piquero, Macintosh, \& Hickman, 2000). Removal of these items reduced the alphas to .9009 and .8918 , respectively. Also, as Grasmick et al. found, the Physical Activities subscale was the weakest element of self-control ([alpha] $=.72$ ) in the exploratory factor analysis. Taken as a whole, we see no consistent justification for removing items at the expense of theoretical accuracy. We retained all items in the scale to preserve its original measurement.

3 Using data from the National Youth Survey and confirmatory factor analyses, Greenberg et al. (2002) discontinued Gottfredson and Hirschi's claim that self-control is the primordial cause of disparate acts of deviance. This is an important finding and the first to suggest that diverse criminal acts may have diverse etiologies, an idea that is antithetical to self-control theory. However, we assessed two different dependent variables to remain consistent with the original theoretical ideas and the majority of the literature that supports it.

4 Kline (1998) suggested that four statistical tests should be used to access model fit in an SEM. We used seven. While various goodness-of-fit statistics can yield disparate information on the same model (see Fan, Thompson, \& Wang, 1999), we used multiple statistics to examine the Grasmick et al. scale in the most stringently empirical manner. Such a rigorous approach is necessary for measure validation.

5 Full output is available from us on request. Also, the dimensions remained highly correlated with each other, as did the individual items with the dimensions.

6 Correlations between the self-control dimensions range from $\mathrm{r}^{\wedge}$ sub self.centered-simple tasks ${ }^{\wedge}$ $=.19$ to $\mathrm{r}^{\wedge}$ sub simple tasks -temper $\mathrm{r}^{\wedge}=.74$. The average correlation between dimensions is $\mathrm{r}=$ .50 , far below conventional standards for asserting unidimensionality.

7 Beyond self-control, the study produced mixed findings regarding other correlates of prison misconduct. For example, we found that whites were more involved in prison misconduct, a finding that is contrary to the findings of prior research (Harer \& Steffensmeier, 1996; Poole \& Regoli, 1980, 1983; Wooldredge, Griffin, \& Pratt, 2001). Perhaps the current findings are due to the relative homogeneity of the sample (e.g., rural, mostly white men).

\section{REFERENCES}

Arneklev, B. J., Grasmick, H. G., \& Bursik, Jr., R. J. (1999). Evaluating the dimensionality and invariance of "low self-control." Journal of Quantitative Criminology, 15, 307-331. 
Arneklev, B. J., Grasmick, H. G., Tittle, C. R., \& Bursik, Jr., R. J. (1993). Low self-control and imprudent behavior. Journal of Quantitative Criminology, 9, 225-247.

Avakame, E. F. (1998). Intergenerational transmission of violence, self-control, and conjugal violence: A comparative analysis of physical violence and psychological aggression. Violence and Victims, 13, 301-316.

Bartusch, D. J., Lynam, D., Moffitt, T. E., \& Silva, P. A. (1997). Is age important? Testing a general versus a developmental theory of antisocial behavior. Criminology, 35, 13-48.

Britt, C. L. (2000). Comment on Paternoster and Brame. Criminology, 38, 965-970.

Brownfield, D., \& Sorenson, A. M. (1993). Self-control and juvenile delinquency: Theoretical issues and an empirical assessment of selected elements of a general theory of crime. Deviant Behavior, 14, 243-264.

Burton, V. S., Jr., Cullen, F. T., Evans, T. D., Fiftal-Alarid, L., \& Dunaway, R. G. (1998). Gender, self-control, and crime. Journal of Research in Crime and Delinquency, 35, 123-147.

Cochran, J. K., Wood, P. B., Sellers, C. S., Wilkerson, W., \& Chamlin, M. B. (1998). Academic dishonesty and low self-control: An empirical test of a general theory of crime. Deviant Behavior, 19, 227-255.

DeLisi, M. (2001a). Designed to fail: self-control and involvement in the criminal justice system. American Journal of Criminal Justice, 26, 131-148.

DeLisi, M. (2001b). It's all in the record: Assessing self-control theory with an offender sample. Criminal Justice Review, 26, 1-16.

Fan, X., Thompson, B., \& Wang, L. (1999). Effects of sample size, estimation Methods, and model specification on structural equation modeling fit indexes. Structural Equation Modeling, 6, 56-83.

Forde, D. R., \& Kennedy, L. W. (1997). Risky lifestyles, routine activities, and the general theory of crime. Jstice Quarterly, 14, 265-294.

Geis, G. (2000). On the absence of self-control as the basis for a general theory of crime: A critique. Theoretical Criminology, 4, 35-53.

Gerbing, D, W., \& Hamilton, J. G. (1996). The viability of exploratory factor analysis as a precursor to confirmatory factor analysis. Structural Equation Modeling, 3, 62-72.

Gibbs, J. J., \& Giever, D. (1995). Self-control and its manifestations among university students: An empirical test of Gottfredson and Hirschi's general theory. Justice Quarterly, 12, 231-256. 
Gibbs, J. J., Giever, D., \& Martin, J. S. (1998). Parental management and self-control: An empirical test of Gottfredson and Hirschi's general theory. Journal of Research in Crime and Delinquency, 35, 40-70.

Gibson, C., \& Wright, J. (2001). Low self-control and coworker delinquency: A research note. Journal of Criminal Justice, 29, 483-492.

Gottfredson, M. R., \& Hirschi, T. (1990). A general theory of crime. Stanford, CA: Stanford University Press.

Grasmick, H. G., Tittle, C. R., Bursik, Jr., R. J., \& Arneklev, B. J. (1993). Testing the core empirical implications of Gottfredson and Hirschi's general theory of crime. Journal of Research in Crime and Delinquency, 30, 5-29.

Greenberg, D. F. (2000, September). The "number of factors" problem in structural equation modeling. Paper presented at the annual meeting of the International Sociological Association, Cologne, Germany.

Greenberg, D. F., Tamarelli, R., \& Kelley, M. S. (2002). The generality of the self-control theory of crime. Advances in Criminological Theory, 10, 49-94.

Harer, M., \& Steffensmeier, D. (1996). Race and prison violence. Criminology, 34, 323-355. Hay, C. 2001. Parenting, self-control, and delinquency: A test of self-control theory. Criminology, 39, 707-736.

Hirschi, T., \& Gottfredson, M. (1983). Age and the explanation of crime. American Journal of Sociology, 89, 552-584.

Hirschi, T., \& Gottfredson, M. R. (1989). The significance of white-collar crime for a general theory of crime. Criminology, 27, 359-371.

Hirschi, T., \& Gottfredson, M. R. (1993). Commentary: Testing the general theory of crime. Journal of Research in Crime and Delinquency, 30, 47-54.

Hirschi, T., \& Gottfredson, M. R. (1995). Control theory and the life-course perspective. Studies on Crime and Crime Prevention, 4, 131-142.

Hu, L., \& Bentler, P. M. (1999). Cutoff criteria for fit indices in covariance structure analysis: Conventional criteria versus new alternatives. Structural Equation Modeling, 6, 1-55.

Junger, M., \& Tremblay, R. (1999). Self-control, accidents, and crime. Criminal Justice and Behavior, 26, 485-501.

Keane, C., Maxim, P. S., \& Teevan, J. J. (1993). Drinking and driving, self-control, and gender: Testing a general theory of crime. Journal of Research in Crime and Delinquency, 30, 30-46. 
Kline, R. B. (1998). Principles and practice of structural equation modeling. New York: Guilford Press.

LaGrange, T. C., \& Silverman, R. A. (1999). Low self-control and opportunity: Testing the general theory of crime as an explanation for gender differences in delinquency. Criminology, 37, 41-72.

Li, F., Duncan, T. E., Harmer, P., Acock, A., \& Stoolmiller, M. (1998). Analyzing measurement models of latent variables through multilevel confirmatory factor analysis and hierarchical linear modeling approaches. Structural Equation Modeling, 5, 294-306.

Longshore, D. (1998). Self-control and criminal opportunity: A prospective test of the general theory of crime. Social Problems, 45, 102-113.

Longshore, D., Stein, J. A., \& Turner, S. (1998). Reliability and validity of a self-control measure: A rejoinder. Criminology, 36, 175-182.

Longshore, D., \& Turner, S. (1998). Self-control and criminal opportunity: Cross-sectional test of the general theory of crime. Criminal Justice and Behavior, 25, 81-98.

Longshore, D., Turner, S., \& Stein, J. A. (1996). Self-control in a criminal sample: An examination of construct validity. Criminology, 34, 209-228.

Maxfield, M. G., \& Babbie, E. (2001). Research methods for criminal justice and criminology (3rd ed.). Belmont, CA: Wadsworth.

Moffitt, T. E., Krueger, R., Caspi, A., \& Fagan, J. (2000). Partner abuse and general crime: How are they the same? How are they different? Criminology, 38, 199-232.

Nagin, D. S., \& Paternoster, R. (1993). Enduring individual differences and rational choice theories of crime. Law and Society Review, 27, 467-496.

Paternoster, R., \& Brame, R. (1997). Multiple routes to delinquency? A test of developmental and general theories of crime. Criminology, 35, 49-84.

Piquero, A. R., MacIntosh, R., \& Hickman, M. (2000). Does self-control affect survey response? Applying exploratory, confirmatory, and item response theory analysis to Grasmick et al.'s selfcontrol scale. Criminology, 38, 897-930.

Piquero, A. R., \& Rosay, A. B. (1998). The reliability and validity of Grasmick et al.'s selfcontrol scale: A comment on Longshore et al. Criminology, 36, 157-174.

Piquero, A., \& Tibbetts, S. (1996). Specifying the direct and indirect effects of low self control and situational factors in offenders' decision making: Toward a more complete model of rational offending. Justice Quarterly, 13, 481-510. 
Polakowski, M. (1994). Linking self- and social control with deviance: Illuminating the structure underlying a general theory of crime and its relation to deviant activity. Journal of Quantitative Criminology, 10, 41-78.

Poole, E. D., \& Regoli, R. M. (1980). Race, institutional rule breaking, and disciplinary response: A study of discretionary decision making in prison. Law and Society Review, 14, 931946.

Poole, E. D., \& Regoli, R. M. (1983). Violence in juvenile institutions: A comparative study. Criminology, 21, 213-232.

Pratt, T. C., \& Cullen, F. T. (2000). The empirical status of Gottfredson and Hirschi's general theory of crime: A meta-analysis. Criminology, 38, 931-964.

Sampson, R. J., \& Laub, J. H. (1993). Crime in the making: Pathways and turning points through life. Cambridge, MA: Harvard University Press.

Sampson, R. J., \& Laub, J. H. (1995). Understanding variability in lives through time:

Contributions of life-course criminology. Studies on Crime and Crime Prevention, 4, 143-158.

Schreck, C. (1999). Criminal victimization and low self-control: An extension and test of a general theory of crime. Justice Quarterly, 16, 633-654.

Sellers, C. (1999). Self-control and intimate violence: An examination of the scope and specification of the general theory of crime. Criminology, 37, 375-404.

Silvia, E. S. M., \& MacCallum, R. C. (1988). Some factors affecting the success of specification searches in covariance structure modeling. Multivariate Behavioral Research, 23, 297-326.

Steiger, J. H. (1998). A note on multiple sample estimation of the RMSEA fit index. Structural Equation Modeling, 5, 411-419.

Steiger, J. H. (2000). Point estimation, hypothesis testing, and interval estimation using the RMSEA: Some comments and a reply to Hayduck and Glaser. Structural Equation Modeling, 7, 149-162.

Tibbetts, S. G., \& Myers, D. L. (1999). Low self-control, rational choice, and student test cheating. American Journal of Criminal Justice, 23, 179-200.

Van Wyk, J. A., Benson, M. L., \& Harris, D. K. (2000). A test of strain and self-control theories: Occupational crime in nursing homes. Journal of Crime and Justice, 23, 27-44.

Vazsonyi, A. T., Pickering, L. E., Junger, M., \& Hessing, D. (2001). An empirical test of a general theory of crime: A four-nation comparative study of self-control and the prediction of deviance. Journal of Research in Crime and Delinquency, 38, 91-131. 
Winfree, L. T., \& Bernat, F. P. (1998). Social learning, self-control, and substance abuse by eighth grade students: A tale of two cities. Journal of Drug Issues, 28, 539-558.

Wood, P. B., Cochran, J. K, Pfefferbaum, B., \& Arneklev, B. J. (1995). Sensation-seeking and delinquent substance use: An extension of learning theory. Journal of Drug Issues, 25, 173-193.

Wood, P. B., Pfefferbaum, B., \& Arneklev, B. J. (1993). Risk-taking and self-control: Social psychological correlates of delinquency. Journal of Crime and Justice, 16, 111-130.

Wooldredge, J., Griffin, T., \& Pratt, T. (2001). Considering hierarchical models for research on inmate behavior: Predicting misconduct with multilevel data. Justice Quarterly, 18, 203-231.

Wright, B. R. E., Caspi, A., Moffitt, T. E., \& Silva, P. (1999). Low self-control, social bonds, and crime: Social causation, social selection, or both? Criminology, 37, 479-514.

Wright, J. P., \& Cullen, F. T. (2000). Juvenile involvement in occupational delinquency. Criminology, 38, 863-896. 